\title{
Nutrition knowledge, attitude and practices among urban primary school children in Nairobi City, Kenya: a KAP study
}

\author{
Dorcus Mbithe D. Kigaru' ${ }^{1 *}$, Cornelia Loechl², Thabisile Moleah², C. W. Macharia-Mutie ${ }^{3}$ and Zipporah W. Ndungu
}

\begin{abstract}
Background: Kenya is undergoing rapid urbanization resulting in changing lifestyles. Childhood dietary habits are changing and might result in childhood obesity and related health risks. Dietary habits learnt in early life are likely to be carried to adulthood. Nutrition knowledge and positive attitude are known to influence dietary practices. There is paucity of information on nutrition knowledge, attitude and practices of school-children in cities. This study established nutrition knowledge, attitude and practices among urban school children in Nairobi.
\end{abstract}

Methods: A cross-sectional study was conducted among 202 school-children aged 8-11 years, systematically sampled from four randomly selected schools. Structured questionnaire, key informant interviews and focus group discussions were used to collect data. A nutrition knowledge score was determined (correct response: 1, incorrect: 0). Overall knowledge level was the total of correct responses in percentages. Scores of $\leq 40 \%$, 41-69\% and $\geq 70 \%$ were categorized as low, moderate and high knowledge respectively. Dietary practices were determined from frequency of food consumption, habitual patterns and attitude on what they ate. Data were analyzed using SPSS. P-value of $p<0.05$ was considered significant.

Results: Pupils had moderate nutrition knowledge (mean score 5.16 $\pm 1.6,51.6 \%$ ). $65 \%$ did not care what they ate. About $82 \%$ ate food in front of TV unsupervised. Over $70 \%$ had consumed sweetened beverages and $73 \%$ junk foods in previous 7 days. Only $9 \%$ consumed fruits 4-7 times a week. Almost all study children carried money to school and made decision on foods to buy. Chips, candies, sausages and smokies, doughnuts and chocolate were preferred snacks. Nutrition knowledge had no significant relationship with dietary practices, but attitude had.

Conclusion: Children had moderate nutrition knowledge and poor dietary practices, associated with negative dietary attitude. This study recommends activities to raise awareness on the effect of poor dietary practices on obesity and related health risks.

Keywords: Nutrition knowledge, Dietary practices, School children, Urban primary schools

\section{Background}

Poor dietary practices are major contributors to the development of chronic non-communicable diseases $[1,2]$. Kenya is a sub-Saharan country undergoing rapid urbanization resulting in changing lifestyles and dietary habits; the so-called nutrition transition [3, 4]. Most chronic diseases in adulthood originate from

\footnotetext{
* Correspondence: dorcusmbithe@yahoo.com

${ }^{1}$ Kenyatta University, Department of Food, Nutrition and Dietetics, PO BOX

43844-00100, Nairobi, Kenya

Full list of author information is available at the end of the article
}

dietary practices which are mainly formed during childhood [5-7]. In order to promote healthier eating habits, nutrition knowledge is believed to be important [8]. However, nutrition knowledge alone may not be sufficient to change dietary habits hence in addition there is need to mold a positive attitude toward healthy eating early in childhood [9-11]. With the current change in dietary habits to the western diet and increase in televised food advertisements targeting children, there is even greater need to empower children with the right knowledge and 
attitudes for making proper food choices [12]. School age children spend more time away from their parents thus, influence from friends and media further affect the formation and stabilization of their dietary practices [13, 14].

There is growing evidence suggesting that young children from developing countries are increasingly making unhealthy food choices especially due to lack of knowledge and wrong perception towards healthy foods $[11,15]$. This is mainly because presently the concept of 'food' has changed from a means of nourishment to a marker of lifestyle and a source of pleasure as portrayed by media [16]. A large proportion of televised food advertisements are of highly processed foods/convenient foods with, high caloric content, large amounts of fat and sugar, and with little or no micronutrient content [14]. In addition, children in urban centres such as Nairobi, the capital city of Kenya have easy access to numerous fast food outlets, restaurants and supermarkets, and they are left to make decisions on what to eat [17]. Therefore, to be able to overcome the emerging issue of obesity and overweight among children and related health risks, school children have to be empowered to make the right food choices by providing them with nutrition knowledge and changing their attitudes towards healthy eating. A larger study was conducted to assess nutritional status, including body composition, blood pressure, and physical activity levels, along with nutritional knowledge, attitude and dietary practices of school going children in four urban schools in Nairobi Kenya. This article presents the findings on the nutrition knowledge, practices and attitudes.

\section{Methods}

The study adopted a cross-sectional study design which was conducted among children aged 8-11 years from four randomly selected day public primary schools in Kasarani Sub-county in Nairobi city. The city was purposively selected due to rapid urbanization, transition in dietary practices and lifestyle. Kasarani sub-county was randomly selected. Four primary schools were randomly selected from 17 day public primary schools in the selected sub-county. Proportionate to size sampling was used to sample 202 children. At the school level stratified random sampling was used to select children from each age group 8 years, 9 years, 10 years and 11 years. A representation ratio of boys to girls as 1:1 was anticipated.

A structured questionnaire with a with figure-rating scale for girls (silhouettes) validated and widely used in other studies [18, 19], a head teacher key informant interview (KII) guide and a focus group discussion (FGD) guide were used to collect data. All data collection instruments were pretested in a fifth school that was not part of the main study. The questions were designed based on the research objectives of the larger study. The study pupils filled the questionnaires under the supervision of the researchers who ensured that all the children responded to the study questions. FGDs were conducted to get more information on knowledge, attitude and dietary practices of the children towards healthy eating. Two FGDs per school each comprising of 8 children were researcher facilitated. The research assistant recorded all the deliberations of the discussion. The researcher ensured that the selected venues were comfortable and free from disturbance. Deliberate efforts were made to ensure discussion questions followed each other as they appeared in the guide. To achieve a balanced discussion the facilitator moderated the discussions. The discussions took an average of one hour. Key informant interviews were held with the head teachers of the participating schools to get in depth information on the school environment in terms of promoting healthy dietary practices.

The level of nutrition knowledge was determined using 10 multiple choice questions concerning food, nutrition and healthy eating. For each question, a correct response was coded as 1 and an incorrect response as 0 . The total score for every child was calculated from all correct responses with a maximum of 10 . This was then converted to a percentage. Those who scored below $40 \%$ were categorized as having low nutrition knowledge, 41-69 \% moderate, and $>70 \%$ high nutrition knowledge which was predetermined before the study.

A food frequency questionnaire (FFQ) with foods arranged into 9 categories based on food grouping was used to assess dietary practices. A list of commonly available soft drinks and fast foods were provided for the children to indicate the frequency of consumption in the last seven days prior to the study [20]. Total frequency of consumption of all sweetened drinks, fast foods and fruits was computed. Consumption of sweetened beverages, fruits and fast foods more than four times in a week was considered excess consumption while consumption of fruits less than four times in a week was considered inadequate intake as provided by Food and Nutrition Technical Assistance [21]. In addition, eating habits like eating in front of the television (TV), eating with other family members, eating breakfast and sharing food in school with other children and presence of food vendors in the school were used to assess influence of home and school environment to children's dietary practices. To assess the attitude towards good dietary practices, the study children were asked whether they were concerned about what they ate.

Data were analysed using SPSS version 20 [22, 23]. Pearson product moment correlation and chi-square 
tests were used to establish relationships and associations between nutrition practice, knowledge and attitude. Results were considered significant at $P<0.05$. Qualitative data from FGD and KII were coded by assigning labels to variable categories. Common themes were then established and clustered in a patterned order to clarify variables. Inferences were made from particular data under each theme then conclusions were drawn from the findings. The findings were triangulated with the reported quantitative data. The study was approved by the Kenyatta University Ethical Review Committee. Written informed consent was sought from the children's parents and assent sought from the study children.

\section{Results}

\section{Demographic characteristics of study pupils}

The age distribution of the study population was between $8-11$ years with majority (40.6\%) being 11 years. Mean age was $10.07 \pm 0.9 \mathrm{SD}$. Most of the study pupils were girls $(54.0 \%)$ while boys were $46.0 \%$. There was no significant difference $(P>0.05)$ between sexes. The average household size was $4.9 \pm 1.4$ SD with maximum of nine members and minimum of two members in a household. Majority (28.2 \%) of the household's had five household members. Most (79.7 \%) households had fathers as household head with only a few $(20.3 \%)$ were being headed by females (Table 1).

Table 1 Demographic characteristic of the study pupils

\begin{tabular}{llll}
\hline & Characteristics & Number & Percent (\%) \\
\hline Sex & Boys & 93 & 46.0 \\
& Girls & 109 & 54.0 \\
& Total & 202 & 100 \\
& 8 & 15 & 7.4 \\
& 9 & 38 & 18.8 \\
& 10 & 67 & 33.2 \\
Household size & 11 & 82 & 40.6 \\
& Total & 202 & 100 \\
& 2 & 4 & 4.0 \\
& 3 & 25 & 12.4 \\
& 4 & 46 & 22.8 \\
& 5 & 57 & 28.2 \\
& 6 & 41 & 20.3 \\
& 7 & 16 & 7.9 \\
& $>8$ & 9 & 4.5 \\
Household head & Total & 202 & 100 \\
& Fathers & 183 & 79.7 \\
& Mothers & 19 & 20.3 \\
& Total & 202 & 100 \\
\hline
\end{tabular}

\section{Nutrition knowledge of the study pupils'}

Results from this study showed that close to half (49.5 \%) had moderate knowledge, about $32.7 \%$ had low knowledge while $17.8 \%$ had high knowledge (Table 2).

The mean knowledge score was $5.16 \pm 1.6 \mathrm{SD}$ with a minimum of 1 point and maximum of 9 points, with lower quartile as 4 , medium as 5 and upper quartile being 6 which indicated that pupils had moderate nutrition knowledge. This was despite the fact that all schools had lessons where healthy eating was taught as confirmed by the pupils' responses in the questionnaire and the key informants. The study established the proportion of pupils who responded correctly on various test questions (Table 3). This was mainly to identify which aspects of the knowledge aspects pupil's were weaker or stronger. Majority of the children (90.6\%) knew that fruits are healthy snacks and that consumption of too much fat can make someone become fat (62.4\%), while consumption of fruits and vegetables daily is good for body to fight against illnesses (74.3\%). Most children (88.1\%) knew that sugar, sweets and sweet foods are not good for health. However, most (77.2 \%) were not aware that over consumption of sugary foods can make someone fat. Other nutrition aspects tested included the role of various food groups in the body. According to this study, pupils were found to be weak in identifying the role of various food groups in the knowledge test. Only $21 \%$ were able to correctly identify the best source of energy food group while $54 \%$ could not identify the group of nutrients that is good for building body muscles. Only $46 \%$ of the study children knew that sweets and sugary foods should be least consumed. This shows that most children had minimal knowledge on nutrient classification and their functions in the body.

\section{Attitude toward healthy eating}

The study pupils were asked their feelings towards what they ate. Only $35.1 \%$ of them reported that they were concerned about the foods eaten, while $64.9 \%$ of them reported that they did not care about what they ate since they were still young. Figure rating scale established that more than half of the girls (59.6\%) had the perception that they were of lean size despite some of them being big from observation. A similar proportion (52.3\%) felt that they wanted to remain in that body shape, therefore felt no need to check their diet in relation to their body

Table 2 Nutrition knowledge level among the school children

\begin{tabular}{lll}
\hline Nutrition knowledge (percentage) & Number & Percent \\
\hline Low $(<40)$ & 66 & 32.7 \\
Moderate (41-69) & 100 & 49.5 \\
High $(>70)$ & 36 & 17.8 \\
Total & 202 & 100 \\
\hline
\end{tabular}


Table 3 Proportions of respondents with correct scores in various nutrition knowledge aspects

\begin{tabular}{lllc}
\hline & Nutrition knowledge aspect tested & Number & \% correct answers \\
\hline 1 & Fruits are healthy snacks & 183 & 90.6 \\
2 & $\begin{array}{l}\text { When you eat too much fat you } \\
\text { can become fat }\end{array}$ & 126 & 62.4 \\
$3 \quad \begin{array}{l}\text { Is eating fruit and vegetables every } \\
\text { day good for our bodies to fight } \\
\text { against illnesses like colds and flu? }\end{array}$ & 750 & 74.3 \\
$4 \quad \begin{array}{l}\text { Eating a lot of sugar, sweets and } \\
\text { sweet food, is good for health }\end{array}$ & 178 & 88.1 \\
$5 \quad \begin{array}{l}\text { Eating a lot of sugar, sweets and } \\
\text { sweet food can make you fat }\end{array}$ & 46 & 22.8 \\
$6 \quad \begin{array}{l}\text { Food group that you should eat } \\
\text { the most of every day }\end{array}$ & 62 & 30.7 \\
7 & $\begin{array}{l}\text { Food group that you should eat } \\
\text { the least of every day }\end{array}$ & 93 & 46.0 \\
8 & $\begin{array}{l}\text { Food group that gives your body } \\
\text { the best energy }\end{array}$ & 43 & 21.3 \\
9 & $\begin{array}{l}\text { Food group that your body uses } \\
\text { to build muscles }\end{array}$ & 93 & 46.0 \\
10 & $\begin{array}{l}\text { Food group that best protects } \\
\text { the body against illnesses }\end{array}$ & 124 & 61.3 \\
\hline
\end{tabular}

size and shape. From the FGDs, boys had a perception that being thin is not good since other boys would bully them and this made them eat a lot of food to be energetic in case other boys want to fight them.

\section{Dietary practices}

\section{Frequency of consumption of various foods among the children}

From a 7 day food frequency questionnaire, $28 \%$ of the children consumed sweetened drinks 4-7 times in a week while $49.0 \%$ consumed sweetened drinks 1-3 times in a week. Fast foods were consumed by $40.6 \%$ of study children 4-7 times and $32.7 \% 2-3$ times in a week. Some of the soft sweetened drinks consumed by the study children were carbonated sweet drinks (sodas) and artificial juices such as Afia, Quencher, Minute maid (brand names). Fast foods consumed by the children were smokies, sausages, chips (French fries), fatty doughnuts (mandazi) sweets, cakes, chocolate and popcorns.
Regarding consumption of fruits, only $9.4 \%$ had consumed fruits 4-7 times in the previous 7 days prior to data collection as reported from food frequency questionnaire. About $33.2 \%$ had consumed fruits 2-3 times in 7 days while $48.5 \%$ had consumed fruits only once in 7 days (Table 4). Follow up questions showed that of those who had consumed fruits, $49 \%$ ate fruits because of the sweet taste, while $17.3 \%$ ate fruits because they were told by parents to eat them. About $33.7 \%$ of the children reported to eat fruits because they saw other family members eat them. Consumption of other healthy snacks like nuts and milk (not in tea) was assessed. It was noticed that although nuts such as groundnuts were available and packaged in small and affordable portions, most children never consumed them. More than half (59.9 \%) had not consumed nuts even a single time in the last seven days prior to the study. Milk on its own had been consumed only once by $61.4 \%$ of the study children. Complementary findings from focus group discussion showed that study children preferred to buy processed juices and carbonated sweet drinks rather than milk. From the FGDs, it was noted that most of these soft drinks were consumed mainly away from home, when the pupils were going to or coming back from school. Children who did not carry packed lunch were given money to carry to school to buy either lunch or snacks. Children did not report back to their parents what type of food and/or snacks they bought while at school and therefore parents were not aware of the foods that their children consumed outside home especially snacks.

\section{Snacking habits of the study children}

To establish whether study children were able to make informed choices on healthy snacks, they were asked what they usually ate when they felt like snacking. The findings are presented in Table 5.

The most preferred snacks were potato chips (78.2\%) and chocolate (69.3\%). Other commonly preferred snacks by children were cakes, sandwiches, sweets, smokies (smoked sausage), sausages, and popcorn (Table 5). Fruits like an apple or nuts were indicated only a few times. This shows that children did not engage much in healthy snacking. From FGDs, children

Table 4 Frequency of consumption of various food items in the last 7-days

\begin{tabular}{|c|c|c|c|c|c|c|c|c|}
\hline \multirow[t]{2}{*}{ Food group } & \multicolumn{2}{|c|}{ 4-7 times } & \multicolumn{2}{|c|}{$2-3$ t/times } & \multicolumn{2}{|c|}{ once } & \multicolumn{2}{|c|}{ Not consumed in the last 7 days } \\
\hline & $\bar{N}$ & $\%$ & $n$ & $\%$ & $\mathrm{n}$ & $\%$ & $n$ & $\%$ \\
\hline Fruits & 19 & 9.4 & 67 & 33.2 & 98 & 48.5 & 17 & 8.4 \\
\hline Nuts & 3 & 1.5 & 24 & 11.9 & 54 & 26.7 & 121 & 59.9 \\
\hline Milk & 24 & 11.9 & 43 & 21.3 & 124 & 61.4 & 11 & 5.4 \\
\hline Sweetened drinks & 57 & 28.2 & 72 & 35.6 & 27 & 13.4 & 46 & 22.8 \\
\hline Fast foods & 82 & 40.6 & 66 & 32.7 & 0 & 0.0 & 54 & 26.7 \\
\hline
\end{tabular}


Table 5 Choice of snacks made by the study children

\begin{tabular}{lll}
\hline Food/snack* & Number & Percent \\
\hline Chips (French fries) & 158 & 78.2 \\
Sweets & 105 & 52.0 \\
Sandwich & 110 & 54.4 \\
Chocolate & 140 & 69.3 \\
Cakes & 116 & 54.7 \\
Popcorns & 82 & 40.5 \\
Sausages & 83 & 41.1 \\
Smokies (smoked sausage) & 103 & 51.0 \\
\hline
\end{tabular}

*Multiple responses were allowed in this question

reported that they consumed the mentioned food items mainly because of the sweet taste. In addition, children reported that while away from home they would tend to buy snacks, which were usually not found at home. Availability of cheap fast foods and sweet beverages in the environment surrounding the school encouraged their consumption among the pupils. Other practices associated with food intake while at school were carrying of packed lunch to school which was often shared among the pupils and carrying money to school for buying lunch or snacks (Table 6).

From the results, $68.3 \%$ children carried lunch box daily to school. The study noted that majority of those who carried lunch to school (77.3 \%) usually shared with other children. This shows that what children ate was also greatly influenced by what other children carry to school. Almost all of the study children $(95.5 \%$ ) carried money to school to buy either mid morning snacks or lunch for those who did not carry lunch box to school. All schools had a parent-funded feeding program whose participation was not compulsory as reported by key informants hence most children preferred carrying lunch box to school and/or money to buy food. From the key

Table 6 Practices associated with food intake

\begin{tabular}{llll}
\hline Variable & & Frequency & Percent \\
\hline Carry lunch box & Yes & 138 & 68.3 \\
& No & 48 & 23.8 \\
& Sometimes (2-3 times & 16 & 7.9 \\
& per week) & & \\
& Total & 202 & 100 \\
Share lunch with others & Yes & 99 & 64.3 \\
& No & 35 & 22.7 \\
& Sometimes (2-3 times & 20 & 13.0 \\
& a week) & & \\
& Total & 160 & 100.0 \\
Carry money to school & Yes & 193 & 95.5 \\
& No & 9 & 4.5 \\
& Total & 202 & 100 \\
\hline
\end{tabular}

informants, there were many food vendors adjacent to the schools. The schools did not have food policy to regulate food items sold in the surrounding shops. Key informants reported that children had easy access to variety of snacks from the shops. Moreover, the schools did not have shops within the school compound and therefore children relied on what was available in the surrounding shops. In addition, the products were also easily available and in various packaging sizes, which children would afford.

\section{Eating environment at home}

Eating environment at home was also assessed. Most of the children $(82.1 \%)$ ate food in front of the TV at home, either daily or at least 2-3 times in a week (Table 7). Moreover, about $32.2 \%$ of the study children ate their food in the absence of their parents, either always or sometimes (at least 2-3 times in a week). This is an indication that most children ate food unsupervised. In this study, breakfast was consumed by the majority of children (92.1\%), although the quality of the breakfast is not reported in this paper.

\section{Relationship between nutrition knowledge, attitude and practices}

Nutrition knowledge had no significant relationship $(P>0.05)$ with dietary practices (Table 8$)$. Attitude was found to have a significant relationship $(p<0.05)$ with practices on consumption of sweetened beverages, consumption of fast foods and consumption of fruits (Table 8). This implies that good attitude towards nutrition plays an important role in improving nutrition practices among school children. Children who watched TV were found not to be concerned on what they ate as

Table 7 Eating environment among the study pupils at home

\begin{tabular}{llll}
\hline Home eating environment aspect & Number & Percent \\
\hline Ate in front of TV & Yes & 131 & 64.9 \\
& No & 38 & 18.8 \\
& Sometimes (2-3 times & 33 & 16.3 \\
& a week) & & \\
& Total & 202 & 100 \\
Eating meals with the family & Yes & 137 & 67.8 \\
& No & 22 & 10.9 \\
& Sometimes (2-3 times & 43 & 21.3 \\
& a week) & & \\
& Total & 202 & 100 \\
& Yes & 189 & 92.1 \\
& No & 9 & 4.5 \\
Consumption of breakfast & Sometimes (2-3 times & 7 & 3.5 \\
& a week) & & \\
& Total & 202 & 100 \\
\hline
\end{tabular}


Table 8 Relationship between knowledge, attitude, home environment and dietary practices

$\begin{array}{ll}\begin{array}{l}\text { Relationship between overall nutrition knowledge score and frequency } \\ \text { of food consumption } \\ \text { Sweetened/sugary drinks } \\ \text { Carbonated drink }\end{array} & r=-0.101 ; p=0.061 \\ \text { Artificial juice } & r=-0.112 ; p=0.059 \\ \text { Fast foods } & r=-0.115 ; p=0.062 \\ \text { Chips } & r=-0.157 ; p=0.078 \\ \text { Chocolate } & r=-0.101 ; p=0.061 \\ \text { Sausages } & r=-0.114 ; p=0.060 \\ \text { Doughnuts } & r=-0.129 ; p=0.063 \\ \text { Smokies } & r=-0.165 ; p=0.058 \\ \text { Sweets } & r=-0.154 ; p=0.69 \\ \text { Sandwich } & r=-0.185 ; p=0.06 \\ \text { Popcorns } & r=-0.165 ; p=0.06 \\ \text { Cakes } & r=(0.101-0.170) ; p>0.05\end{array}$

Relationship between attitude and frequency of food consumption

Sweetened/sugary drinks

$\begin{array}{ll}\text { Carbonated drink } & X^{2}=101.7 \mathrm{df}=6, P=<0.001 \\ \text { Artificial juice } & X^{2}=64.738 \mathrm{df}=6, P=<0.001\end{array}$

Fast foods

$\begin{array}{ll}\text { Chips } & X^{2}=70.969 \mathrm{df}=6, P=<0.001 \\ \text { Chocolate } & X^{2}=181.8 \mathrm{df}=6, P=<0.001 \\ \text { Sausages } & X^{2}=185.8 \mathrm{df}=6, P=<0.001 \\ \text { Doughnuts } & X^{2}=71.836, \mathrm{df}=6, P=<0.001 \\ \text { Smokies } & X^{2}=172.0 \mathrm{df}=6, P=<0.001 \\ \text { Sweets } & X^{2}=62.778, \mathrm{df}=6, P=<0.001 \\ \text { Sandwich } & X^{2}=163.7 \mathrm{df}=6, P=<0.001 \\ \text { Popcorns } & X^{2}=111.7 \mathrm{df}=6, P=<0.001 \\ \text { Cakes } & X^{2}=125.5 \mathrm{df}=6, P=<0.001 \\ \text { ruits } & \mathrm{p}>0.05\end{array}$

Relationship between home environment and attitude towards healthy eating

Watching TV $\quad X^{2}=4.5215 \mathrm{df}=1, P=0.002$

Eating with family members $\quad X^{2}=2.5462 \mathrm{df}=1, P<0.001$

compared to those who did not $\left(X^{2}=4.5215 \mathrm{df}=1 p=\right.$ $0.002)$. Children who ate together with parents were found to be concerned of what they ate than those who ate alone $\left(X^{2}=2.5462 \mathrm{df}=1<0.001\right)$.

\section{Discussion}

The aim of this study was to establish nutrition knowledge and attitudes of school going children in relation to dietary practices. Overall, children in this study had moderate nutrition knowledge. in contrast to previous studies which reported low nutrition knowledge among school children [6, 13, 24]. This current finding could be attributed to the fact that at present health lessons were offered in school. School children however felt that they needed not be concerned about what they ate as they were still young.

Nutrition knowledge had no significant relationship with dietary practices in this study. This implies that even though study children had some level of knowledge on the effect of unhealthy diet on their health, they still continued to consume unhealthy diets. This finding is similar to that of another study which found poor dietary practices even among children with good nutrition knowledge [5]. Other studies have shown nutritional knowledge as a factor that influence the decisions individuals make about food [20, 24, 25]. Lack of nutrition knowledge has been implicated as a cause of poor dietary habits [26]. However, knowledge alone may not be adequate to have proper dietary practices. Positive attitude and behaviour change toward healthy eating early in childhood contributes immensely in adopting healthy food habits [8]. Studies also confirm that linking knowledge and practice in nutrition education is a challenge and need behaviour and attitude change [27].

Findings that dietary practices among children were characterized by excess consumption of fast foods and sweetened beverages, an indication of unhealthy food choices and the main reason for consumption of these foods being sweet taste and ease accessibility, are in agreement with other studies which found that young children from developing countries are increasingly making unhealthy food choices especially due to lack of knowledge and negative attitude [15, 28]. Previously, over consumption of sweetened drinks/beverages was a trend observed among American population [29]. However, current studies indicate increased consumption of fast foods among children in developing countries, with increased consumption of sugar-sweetened beverages, contribute to a greater number of total caloric intake and directly to obesity epidemic [29-31]. Contribution of total energy intake from fast foods and sweetened beverage in relation to obesity has been supported by other studies [10, 32, 33]. There is supporting evidence that excessive sugar and fat intake from soft drinks and junk foods increases energy intake, which is likely to increase the risk of overweight and obesity [16].

Availability of cheap snacks in the environment surrounding the school encouraged consumption of the junk foods by the pupils as reported in the FGDs and by the key informants. Other researchers support that easy access to soft drinks from local vendors contribute to their increased consumption [34]. Research has also demonstrated the importance of not only food availability but also accessibility of healthier foods as a measure to promote good dietary practices among children. This 
is because whichever foods are easily accessible and ready to be eaten, children are more likely to eat them [35]. From the focus group discussions, sweet taste was highlighted as among the main reasons for consumption of soft drinks and fast foods. Children in Nairobi have easy access to numerous fast food outlets [17]. Children also reported that some of the sweet snacks such as juices, biscuits, cakes chocolate were hardly bought at home by the parents and therefore once given money for lunch they preferred buying such. In addition, the products were easily available in local kiosks and in various packaging sizes, which children could afford even without the knowledge of the parents. This shows that children have an opportunity to make food choices, thus with good nutrition knowledge and positive attitudes, there exists an opportunity to make healthier choices.

The findings that most children in this study ate their meals at home without parent's supervision are in agreement with other studies that showed that the proportion of school age children spending more time away from their parents is increasing thus parents miss out the opportunity to impact good nutritional knowledge and practices $[8,36]$. Another study showed that about $60 \%$ of 8-12-year-old children chose their own foods yet studies have associated children's eating alone with poor dietary practices due to lack of parental guidance [25]. Family environment has the potential to influence and enhance good dietary practices as children are likely to mimic their parents' practices [37]. Recent research conducted with Irish children indicated that parents were major influencers in their children's diets and that frequency of shared meals has a positive effect on children's food knowledge [38].

Majority of the children in this study ate while watching television and those that had access to TV had higher consumption of fast foods and sweetened beverages. While the television is an avenue for food advertisement and promotion $[39,40]$ most of the televised foods are junk and highly processed with high sugar, fat and salt content. These televised adverts greatly influence dietary habits of children $[40,41]$. A study on chronic non-communicable diseases in Brazil noted that a considerable number of the foods requested by children were advertised on TV during the 6 previous months [1]. Further, another study reported that exposure to TV food advertisement brought negative changes in dietary behaviour especially among school children [36]. In this current study, both quantitative and qualitative methods were used to support this discussion. However, the results in this study are limited to urban day public schools only.

\section{Conclusion}

Children had moderate nutrition knowledge. Knowledge had no association with practices. However, attitude significantly influenced dietary practices. Children did not translate nutrition knowledge into practice. The main factors that influenced dietary practices were mainly the taste of foods (sweet taste) and the feeling that they did not have to be concerned about what they ate since they were still children. This study concludes that there was a disconnect between nutrition knowledge, dietary practices and attitude. Children had money and made independent decisions on what to buy while away from home. At home children mainly ate food alone, unsupervised. Availability of unhealthy snacks contributed to their high consumption.

\section{Recommendation}

Since children at this age make more independent decision on food choices, this study recommends creating awareness on the effect of poor dietary practices on overweight and obesity and associated health risks. This should aim at improving nutrition knowledge, positive attitudes and appropriate dietary practices. Parents are encouraged to monitor their children's eating process and expenditure of pocket money. This study recommends availability tuck shops within the school environment and appropriate policies if school children must bring lunch money to school.

\section{Abbreviations \\ FANTA: Food and nutrition technical assistance; FFQ: Food frequency questionnaire; FGD: Focus group discussion; KIl: Key informant interview; SPSS: Statistical package for social sciences; TV: Television.}

\section{Competing interests}

The authors declare that they have no competing interests.

\section{Authors' contributions}

DMDK, CL and TM conceived the study. DMDK and ZWN with support from $\mathrm{CL}$, TM and CMM collected data, conducted data analysis and interpretation and drafted the manuscript. CL, TM and CMM revised the manuscript. All authors read and approved the final manuscript.

\section{Acknowledgements}

The International Atomic Energy Agency (IAEA) is acknowledged for partial funding of the larger study; RAF6042 in which this study was nested. Also acknowledged is Kenyatta University as the coordination centre. Research assistants and especially Grace Munthali are thanked for their assistance in data collection. The teachers of study schools and study children are greatly thanked for responding to data collection tools. Parents and guardians to the study children are acknowledged for consenting to this study.

\section{Author details}

${ }^{1}$ Kenyatta University, Department of Food, Nutrition and Dietetics, PO BOX 43844-00100, Nairobi, Kenya. ${ }^{2}$ The International Atomic Energy Agency

(IAEA), Nutritional and Health Related Environmental Studies Section, Division of Human Health, Department of Nuclear Sciences and Application, Nairobi, Kenya. ${ }^{3}$ Global Alliance for Improved Nutrition (GAIN), PO Box 13733-00800, Nairobi, Kenya.

Received: 29 July 2015 Accepted: 21 December 2015

Published online: 29 December 2015 


\section{References}

1. Schmidt MI, Duncan BB, Azevedo e Silva G, Menezes AM, Monteiro CA, Barreto SM, et al. Chronic non-communicable diseases in Brazil: burden and current challenges. Lancet. 2011:377(9781):1949-61.

2. WHO/FAO. DIET, NUTRITION AND THE PREVENTION OF Report of a Joint WHO / FAO Expert Consultation. WHO Technical Report Series. 2003:916:1-4

3. Steyn NP, Nel JH, Parker W, Ayah R, Mbithe D. Urbanisation and the nutrition transition: A comparison of diet and weight status of South African and Kenyan women. 2012;229-238. doi:10.1177/1403494812443605.

4. Steyn NP, Nel JH, Parker W, Ayah R, Mbithe D. Dietary, social, and environmental determinants of obesity in Kenyan women. 2011;(2010): 88-97. doi:10.1177/1403494810384426.

5. Abdollahi M, Amini M, Kianfar H, Dadkhah-Piraghag M, Eslami-Amirabadi M, Zoghi T, et al. Qualitative study on nutritional knowledge of primary-school children and mothers in Tehran. East Mediterr Heal J. 2008;14:82-9.

6. Flynn MAT, Mcneil DA, Maloff B, Mutasingwa D, Wu M, Ford C, et al. Reducing Obesity and Related Chronic Disease Risk in Children and Youth: A Synthesis of Evidence with "Best Practice" Recommendations, vol. 7. 2006.

7. Hwenda L. Addressing diet related risk factors for non-communicable diseases. Glob Heal Gov. 2013.

8. Triches RM, Giugliani ERJ. Obesity, eating habits and nutritional knowledge among school children. Rev Saude Publica. 2005;39(4):541-7.

9. Brown R. Children's eating attitudes and behaviour: a study of the modelling and control theories of parental influence. Health Educ Res. 2004; 19(3):261-71. doi:10.1093/her/cyg040.

10. Kim KH. A study of the dietary habits, the nutritional knowledge and the consumption patterns of convenience foods of university students in the Gwangju area. Korean J Community Nutr. 2003;8(2):181-91.

11. Mirmiran P, Azadbakht L, Azizia F. Dietary behaviour of Tehranian adolescents does not accord with their nutritional knowledge. Public Health Nutr. 2007;10(09):897-901.

12. Coon KA, Goldberg J, Rogers BL, Tucker KL. Relationships between use of television during meals and children's food consumption patterns. Pediatrics. 2001;107(1):e7-7. doi:10.1542/peds.107.1.e7.

13. Mbithe DD, Kimiywe JO, Waudo JN, Orodho JA. promotion of nutrition education interventions in rural and urban primary schools in Machakos district. Kenya J Appl Biosci. 2008;6:130-9.

14. Juan PMFS. Dietary habits and nutritional status of school aged children in Spain. Nutr Hosp. 2006;21(3):374-8.

15. Zaborskis A, Lagunaite R, Busha R, Lubiene J. Trend in eating habits among Lithuanian school- aged children in context of social inequality : three cross-sectional surveys 2002, 2006 and 2010. BMC Public Health. 2012;12(1): 52. doi:10.1186/1471-2458-12-52.

16. Dehghan M, Akhtar-danesh N, Merchant AT. Childhood obesity, prevalence and prevention. 2005;8(Table 1):1-8. doi:10.1186/1475-2891-4-24

17. Kyallo F, Makokha A, Mwangi AM. Overweight and obesity among public and private primary school children in Nairobi. Kenya. 2013;5(8):85-90.

18. Tak Y, Cheung D, Lee AM, Ho SY, Tsze E, Li S, et al. Who wants a slimmer body? The relationship between body weight status, education level and body shape dissatisfaction among young adults in Hong Kong. BMC Public Health. 2011;11(1):835. doi:10.1186/1471-2458-11-835.

19. Wertheim EH, Paxton SJ, Tilgner L. Test-retest reliability and construct validity of Contour Drawing Rating Scale scores in a sample of early adolescent girls. Body Image. 2004;1(2):199-205. doi:10.1016/S17401445(03)00024-X

20. Welch AA, Luben R, Khaw KT, Bingham SA. The CAFE computer program for nutritional analysis of the EPIC-Norfolk food frequency questionnaire and identification of extreme nutrient values. Br Diet Assoc. 2005;18:99-116.

21. FANTA/FAO. Guidelines for measuring household and individual dietary diversity, Food Agric Organ United Nations Food Nutr Tech Assist Proj Rome, Italy. 2007. Guidelines.

22. SPSS. IBM SPSS software. 2007. www.spss.com

23. Orodho A. Techniques of Data Analysis Using Statistical Packeges for Social Sciences (SPSS) Computer Programme Version 20. 2009.

24. Phometsi M, Kruger A, Van't Riet $H$. Nutrition knowledge and barriers to good dietary practices among primary school children in a farming community. Dev South Afr. 2006;23(4):529-39.

25. Choi E-S, Shin N-R, Jung E-I, Park H-R, Lee H-M, Song K-H. A study on nutrition knowledge and dietary behavior of elementary school children in Seoul. Nutr Res Pract. 2008;2(4):308-16. doi:10.4162/nrp.2008.2.4.308.
26. Kostanjevec S, Jerman J, Koch V. Nutrition knowledge in relation to the eating behaviour and attitudes of Slovenian schoolchildren. Nutr Food Sci. 2013;43(6):564-72. doi:10.1108/NFS-10-2012-0108.

27. Sherman J, Muehlhoff E. Developing a nutrition and health education program for primary schools in Zambia. J Nutr Educ Behav. 2007;39(6): 335-42. doi:10.1016/j.jneb.2007.07.011.

28. Macdiarmid J, Loe J, Craig LCA, Masson LF, Holmes B, Mcneill G. Meal and snacking patterns of school-aged children in Scotland. Eur J Clin Nutr. 2009; 63(11):1297-304. doi:10.1038/ejcn.2009.87.

29. Duffey KJ, Popkin BM. Shifts in patterns and consumption of beverages between 1965 and 2002. Obesity (Silver Spring). 2007;15(11):2739-47. doi:10.1038/oby.2007.326.

30. Parmar J. Sugar - sweetened beverages and their association with obesity in South Asian children by. MSc. 2014

31. Bray GA, Popkin BM. Dietary sugar and body weight: have we reached crisis in the epidemic of obesity and diabetes?: health be damned! Pour on the sugar. Diabetes Care. 2014;37(4):950-6. doi:10.2337/dc13-2085.

32. Moreno LA, Sarría A, Lázaro A, Bueno M. Dietary fat intake and body mass index in Spanish children 1 - 4. Am J Clin Nutr. 2000;72(5):1399S-1403S.

33. Peltzer K, Pengpid S. Overweight and obesity and associated factors among school-aged adolescents in Ghana and Uganda. Int J Environ Res Public Health. 2011:8:3859-70. doi:10.3390/ijerph8103859.

34. Smith TA, Biing-Hwan L, Jonq-Ying L. Taxing Caloric Sweetened Beverages: Potential Effects on Beverage Consumption, Calorie Intake, and Obesity, ERR-100, U.S. Department of Agriculture, Economic Research Service, July 2010:9-10.

35. Patrick $H$, Nicklas TA. A review of family and social determinants of children's eating patterns and diet quality. J Am Coll Nutr. 2005;24(2): 83-92. doi:10.1080/07315724.2005.10719448

36. Savage JS, Fisher JO, Birch LL. Parental influence on eating behavior. NIH Public Access. 2008;35(1):22-34. doi:10.1111/j.1748-720X.2007.00111.x. Parental.

37. Taylor JP, Evers S, McKenna M. Determinants of healthy eating in children and youth. Can J Public Heal. 2005;96 Suppl 3:20-6. doi:10.2307/41994468.

38. Walsh A, Nelson R. The link between diet and health: an exploratory study of adolescents in Northern Ireland using foodmaps. Int J Consum Stud. 2010:34(2):190-5

39. Grossman M, Tekin E, Wada R. Fast-Food Restaurant Advertising on Television and Its Influence on Youth Body Composition. Natl Bur Econ Res Work Pap Ser. 2012:No. 18640. doi:10.3386/w18640.

40. Harrison K, Bost K. Toward a Developmental Conceptualization of Contributors to Overweight and Obesity in Childhood: The Six C's Model. Child Dev. 2011; 5(1):50-8. http://dx.doi.org/10.1111/j.1750-8606.2010.00150.x.

41. Dixon HG, Scully ML, Wakefield MA, White VM, Crawford DA. The effects of television advertisements for junk food versus nutritious food on children's food attitudes and preferences. Soc Sci Med. 2007;65(7):1311-23. doi:10.1016/j.socscimed.2007.05.011.

\section{Submit your next manuscript to BioMed Central and we will help you at every step:}

- We accept pre-submission inquiries

- Our selector tool helps you to find the most relevant journal

- We provide round the clock customer support

- Convenient online submission

- Thorough peer review

- Inclusion in PubMed and all major indexing services

- Maximum visibility for your research

Submit your manuscript at www.biomedcentral.com/submit 